ISSN: $1858-4837$

E-ISSN: 2598-019X

Volume 13, Nomor 1 (2018),

https://jurnal.uns.ac.id/region

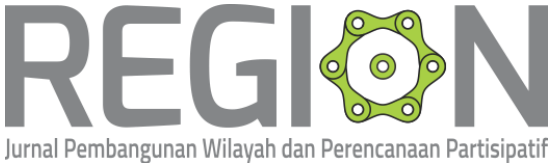

\title{
Komponen Keterpaduan Objek Wisata di Kawasan City Walk Slamet Riyadi Ditinjau dari Sistem Pariwisata
}

\author{
Components of Integration of Tourism Objects in the City Walk Area \\ Slamet Riyadi Judging from the Tourism System
}

\author{
Hafiza Jasmine Azzahra ${ }^{a^{*}}$, Winny Astuti ${ }^{b}$, Erma Fitria Rini $^{c}$ \\ a Program Studi Perencanaan Wilayah dan Kota, Fakultas Teknik, UNS \\ ${ }^{b}$ Program Studi Perencanaan Wilayah dan Kota, Fakultas Teknik, UNS \\ c Program Studi Perencanaan Wilayah dan Kota, Fakultas Teknik, UNS, \\ *Email: hafizazzahra@yahoo.com
}

\begin{abstract}
Abstrak
Pariwisata saat ini adalah kegiatan yang hampir setiap orang di dunia lakukan. Setiap kota mencoba mengembangkan potensi wisata mereka. Salah satu konsep yang bisa dilakukan adalah city walk tourism. Kota Surakarta mendeklarasikan dirinya sebagai kota wisata. Pada tahun 2007, Kota Surakarta merevitalisasi kawasan jalan kota Slamet Riyadi, yang sepanjang jalan, ada beberapa bangunan tua dan objek wisata yang bisa dikunjungi. Sistem pariwisata merupakan hal yang kompleks yang terdiri dari beberapa komponen yang saling berhubungan. Fungsi sistem pariwisata dapat dibagi menjadi dua, dari sisi permintaan dan sisi penawaran, yang memiliki komponen tersendiri. Dengan pembangunan sepanjang jalan kota Slamet Riyadi, yang melewati beberapa objek wisata, momentum ini dapat dimanfaatkan untuk memperbaiki sektor pariwisata di Surakarta. Agar bisa berjalan optimal, maka perlu dilihat apa saja komponen sistem pariwisata yang dibutuhkan tersebut. Metode yang digunakan dalam penelitian ini adalah kajian literatur dan variabel crossing. Metode ini digunakan untuk mengetahui variabel apa saja yang penting dalam sistem pariwisata di jalan kota Slamet Riyadi. Dari kedua metode tersebut maka akan dihasilkan komponen pariwisata terpadu yang berpengaruh terhadap daya tarik wisata Slamet Riyadi.
\end{abstract}

Kata kunci: Komponen Pariwisata, Sistem Pariwisata, Wisata Kota Berjalan

\begin{abstract}
Tourism today is an activity that almost everyone in the world does. Each city tries to develop their tourism potential. One concept that can be carried out is city walk tourism. Surakarta city declares itself as a tourism city. In 2007, the Surakarta Municipality revitalized Slamet Riyadi city walk area, which along the road, there are some old buildings and tourist objects that can be visited. The tourism system is a complex thing that consists of several components that are interconnected. The function of the tourism system can be divided into two, from demand side and supply side, which has its own components. With the construction along Slamet Riyadi city walk, which passes several tourist objects, this momentum can be utilized to improve the tourism sector in Surakarta. In order to run optimally, it is necessary to see what the components of tourism system that required are. The method used in this research is literature review and crossing variables. These methods were used to find out what variables are important in the tourism system at Slamet Riyadi city walk. Of these two methods the output will be the integrated tourism components that influenced in tourist attraction at Slamet Riyadi city walk.
\end{abstract}

Keywords: Tourism Component, Tourism System, City Walk Tourism 


\section{PENDAHULUAN}

Kota merupakan wadah untuk berbagai macam aktivitas manusia yang beragam, salah satunya pariwisata. Ashworth (2003) dalam Hayllar, Griffin dan Edwards (2008) mengidentifikasikan kota sebagai pengaturan yang penting untuk kegiatan pariwisata. Sebagai tempat yang memiliki keanekaragaman sosial, budaya, peninggalan arsitektur, serta dilengkapi dengan berbagai macam fasilitas, kota merupakan tempat yang menarik sebagai tempat pariwisata.

Perkembangan kota menjadi tempat wisata berawal dari ziarah ke tempattempat keramat (keagamaan). Kemudian terjadi Revolusi Industri yang membuat pariwisata menjadi kegiatan massal. Sistem pariwisata merupakan satu hal yang kompleks yang terdiri dari komponen-komponen pariwisata yang saling berhubungan. Menurut Goeldner dan Ritchie [2012:10] pariwisata adalah gabungan dari berbagai aktivitas, pelayanan, perindustrian, dan komponenkomponen lainnya yang menyediakan kebutuhan dan keinginan wisatawan selama berwisata.

Beberapa teori membedakan fungsi sistem pariwisata menjadi dua, dari sisi permintaan dan sisi penawaran [Gunn, 1994; Inskeep, 1991]. Fungsi-fungsi pariwisata tersebut kemudian dibagai ke beberapa komponen. Kota Surakarta saat ini sudah berkembang menjadi salah satu kota besar di Indonesia dan sudah cukup maju. Sebagai kota budaya yang memiliki ciri dan karakteristik kota yang khas karena peninggalan sejarahnya, Kota Surakarta kemudian menjadi kota pariwisata.

Pada tahun 2007, Pemerintah Kota Surakarta juga merevitalisasi kawasan city walk Slamet Riyadi yang mana di koridor jalan tersebut, terdapat beberapa bangunan tua dan objek wisata yang dapat dikunjungi. Momentum ini dapat dimanfaatkan untuk meningkatkan sektor pariwisata di Kota Surakarta. Berdasarkan hal tersebut, penelitian ini ingin melihat bagaimana tingkat keterpaduan objek wisata di kawasan city walk Slamet Riyadi Surakarta ditinjau dari sistem pariwisata.

\section{TINJAUAN PUSTAKA}

\subsection{Definisi Pariwisata}

Bertalanffy mengartikan sistem sebagai kesatuan elemen yang saling terkait didalamnya dan dengan lingkungannya, sebagaimana yang dinyatakan Bertalanffy (1972) dalam Leiper, 1990:21 mengatakan sebagai berikut, " $A$ system may be defined as a set of elements standing in interrelation among themselves and with the 
Region, Vol. 13, No. 1, Januari 2018: 20-36

environments". Sehingga sistem pariwisata dapat diartikan sebagai suatu aktivitas yang kompleks, yang terdiri dari keterkaitan antar komponen yang membentuk sistem pariwisata itu sendiri.

Tabel 1. Sintesis Definisi Sistem Pariwisata

\begin{tabular}{|c|c|c|c|}
\hline Mill dan Morrison (1992) & Fennel (1999) & Gunn (1994) & Sintesis \\
\hline $\begin{array}{l}\text { Sistem pariwisata sebagai } \\
\text { jaring laba-laba. Analogi } \\
\text { ini menggam-barkan } \\
\text { keterkaitan berbagai } \\
\text { komponen sistem } \\
\text { pariwisata yang berbeda- } \\
\text { beda, menyentuh bagian } \\
\text { sistem pariwisata yang lain } \\
\text { dan menginduksi efek riak } \\
\text { ke seluruh jaringan }\end{array}$ & $\begin{array}{l}\text { Tthe interrelated } \\
\text { system that includes } \\
\text { tourists and the } \\
\text { associated services } \\
\text { that are provided and } \\
\text { utilised (facilities, } \\
\text { attractions, } \\
\text { transportation and } \\
\text { accommodation) to } \\
\text { aid in their movement. }\end{array}$ & $\begin{array}{l}\text { Fasilitas-fasilitas ini } \\
\text { (atraksi, } \\
\text { transportasi, } \\
\text { akomodasi) menjadi } \\
\text { bagian dari sistem } \\
\text { pariwisata dan saling } \\
\text { terkait dengan } \\
\text { bagian pariwisata } \\
\text { yang lainnya }\end{array}$ & $\begin{array}{l}\text { Sistem pariwisata } \\
\text { merupakan } \\
\text { kumpulan } \\
\text { komponen } \\
\text { pariwisata yang } \\
\text { memiliki fumgsi } \\
\text { berbeda-beda, } \\
\text { saling terkait dan } \\
\text { mengin-duksi ke } \\
\text { seluruh jaringan }\end{array}$ \\
\hline
\end{tabular}
Sumber: Mill dan Morrison, 1992; Holden, 2000; Fennel, 1999; Gunn, 1994;

Holden, 2000; dan Peneliti, 2017

\subsection{Komponen Pariwisata}

Sistem pariwisata terdiri dari beberapa komponen yang saling terkait untuk memenuhi kebutuhan wisatawan. Dalam mengkaji sistem pariwisata dapat dilihat melalui berbagai pendekatan. Leiper (1990) dalam Pitana (2009), membagi komponen pariwisata menjadi lima komponen, yaitu komponen wisatawan, komponen geografis (traveler-generating region, tourist-destination region, dan transit route region), dan komponen industri pariwisata.

Gunn (1994) melihat sistem pariwisata merupakan sistem yang bekerja sebagai sistem yang fungsional. Dalam sistem fungsional ini, Gunn membedakan menjadi dua sisi, yaitu sisi supply (sediaan) dan sisi demand (permintaan). Gunn mengidentifikasikan penawaran sebagai pasar (market). Pasar ini dipengaruhi oleh orang-orang yang memiliki ketertarikan dan kemampuan untuk berpariwisata. Agar kebutuhan wisatawan dapat terpenuhi, maka dibutuhkan berbagai macam jasa layanan untuk menerima para wisatawan di tempat wisata. Jasa layanan ini kemudian disebut sebagai sisi sediaan. Gunn mengidentifikasi terdapat lima komponen sisi sediaan, yakni atraksi, transportasi, informasi, promosi, dan fasilitas layanan.

McIntosh, Goeldner dan Ritchie (2000) juga melihat sistem pariwisata dari sisi sediaan dan sisi permintaan, dimana sisi permintaan ini merupakan kebutuhan yang dibutuhkan oleh wisatawan selama berkunjung di tempat tujuan. Sedangkan untuk sisi sediaan, McIntosh, Goldner dan Ritchie membagi komponen sistem pariwisata kedalam empat komponen, yakni natural resources, infrastruktur, transportasi dan hospitality and cultural resources. Inskeep (1991) melihat 
Hafiza Jasmine Azzahra dkk, Komponen Keterpaduan Objek... pariwisata sebagai sebuah sistem yang saling terkait satu sama lain. Lebih jauh, Inskeep mengatakan bahwa sistem pariwisata terpadu ini terdiri dari keseimbangan antara sisi permintaan (demand) dan sisi sediaan (supply). Sisi sediaan ini kemudiaan dikatakan sebagai komponen pariwisata.

\subsection{Teori Keterpaduan}

Keterpaduan merupakan suatu keadaan dimana setiap komponen penunjangnya padu atau menjadi satu dan bekerja untuk mencapai tujuan tertentu. Keterpaduan terjadi dengan adanya interaksi yang saling berhubungan atau saling mempengaruhi antara komponen yang satu dengan yang lainnya. Sehingga keterpaduan dalam sistem pariwisata artinya kondisi dimana semua komponen penunjang sistem pariwisata menjadi satu dan saling berinteraksi antar komponennya.

Dari hasil sintesis teori keterpaduan, didapatkan hasil sintesa spasial, kelembagaan, komunitas, dan infrastruktur. Sintesa ini didapatkan dan disesuaikan dengan ruang lingkup dan komponen pariwisata yang disintesa.

\section{METODE PENELITIAN}

Tujuan dari penelitian ini adalah untuk mengetahui komponen objek wisata pada kawasan city walk Slamet Riyadi ditinjau dari sistem pariwisata.

\subsection{Kerangka Teori Penelitian}

Pada penjelasan sebelumnya telah dijelaskan teori-teori yang dipakai dalam penelitian ini. Sebelum menjelaskan mengenai metode yang akan dipakai, penulis akan menyampaikan kerangka teori penelitian. Lebih jelasnya dapat dilihat pada gambar berikut:

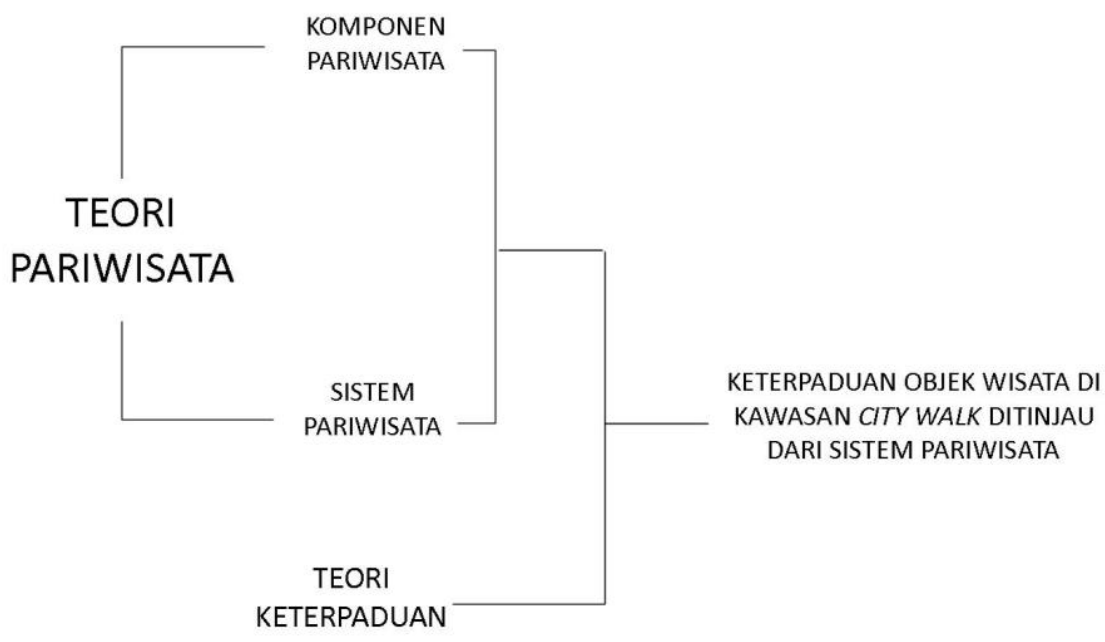

Gambar 1. Kerangka Teori Penelitian (Peneliti, 2017) 


\subsection{Teknik Analisis}

Teknik analisis yang dilakukan dalam penelitian ini adalah peninjauan data pustaka serta persilangan variabel. Hal ini dilakukan guna mendapatkan komponen keterpaduan objek wisata di kawasan city walk Slamet Riyadi Surakarta.

\section{HASIL PENELITIAN DAN PEMBAHASAN}

\subsection{Ruang Lingkup Wilayah}

Kota Surakarta sebagai daerah tujuan wisata memiliki berbagai macam atraksi. Adapun atraksi-atraksi tersebut adalah Taman Balekambang, Kampung Batik Laweyan, Loji Gandrung, Taman Hiburan Sriwedari, Museum Radya Pustaka, Museum Batik Kuno Danar Hadi, Pura Mangkunegaran, Ngarsopuro, Pasar Triwindu, Kampung Batik Kauman, Keraton Kasunanan, Galabo, Benteng Vastenburg, dan Taman Satwa Taru Jurug. Selain persebaran atraksi yang bisa dikunjungi kapan saja, Kota Surakarta juga dikenal sebagai Kota Event, memiliki berbagai macam event atau festival khusus yang diselenggarakan pada tanggal dan tempat tertentu.

Kawasan City Walk Slamet Riyadi Surakarta merupakan kawasan disepanjang Jalan Slamet Riyadi, dari Stasiun Purwosari hingga Pasar Gedhe. Kawasan city walk Slamet Riyadi sendiri terbagi kedalam tujuh segmen. Segmen satu berawal dari Purwosari sampai ke Brengosan. Segmen dua dari Brengosan sampai ke Gendengan. Segmen tiga dari Gendengan sampai Stadion Sriwedari. Segmen empat dari Stadion Sriwedari sampai Ngapeman. Segmen lima dari Ngapeman sampai Jalan Yos Sudarso. Segmen tujuh dari Gladag sampai ke Pasar Gedhe (Putri; Kompas, 2012).

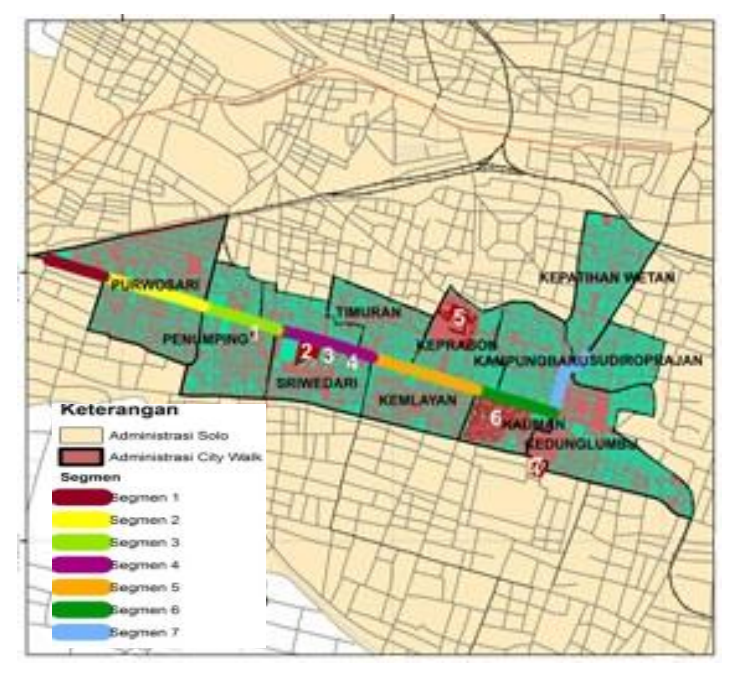

Gambar 2. Ruang Lingkup Wilayah

(Bakosurtanal; Peneliti, 2017) 
Hafiza Jasmine Azzahra dkk, Komponen Keterpaduan Objek...

\subsection{Persilangan Variabel}

Variabel komponen pariwisata disintesis dari penggabungan teori-teori komponen pariwisata yang telah dikemukakan sebelumnya. Sintesis variabel komponen pariwisata dapat dilihat pada Tabel 2.

Tabel 2. Sintesis Variabel Komponen Pariwisata

\begin{tabular}{|c|c|c|c|c|}
\hline Leiper (1990) & Gunn (1994) & $\begin{array}{l}\text { McIntosh, } \\
\text { Goeldner dan } \\
\text { Ritchie (2000) }\end{array}$ & Inskeep (1991) & Sintesis \\
\hline $\begin{array}{l}\text { Transit route } \\
\text { region } \\
\text { Transportasi }\end{array}$ & Transportasi & Transportasi & Transportasi & Transportasi \\
\hline \multirow{4}{*}{$\begin{array}{l}\text { Destination } \\
\text { region } \\
\text { - Atraksi } \\
\text { - Akomodasi } \\
\text { - Toko dan jasa } \\
\text { layanan }\end{array}$} & \multirow[b]{2}{*}{ Atraksi } & Natural Resources & \multirow[b]{2}{*}{ Atraksi } & \multirow[b]{2}{*}{ Atraksi } \\
\hline & & $\begin{array}{ll}\text { Hospitality and } \\
\text { Cultural } \\
\text { Resources }\end{array}$ & & \\
\hline & \multirow[b]{2}{*}{$\begin{array}{l}\text { Jasa Pelayanan } \\
\text { - Hotel } \\
\text { - Rumah makan } \\
\text { - Toko } \\
\text { perbelanjaan }\end{array}$} & & Akomodasi & \multirow[b]{2}{*}{$\begin{array}{l}\text { Fasilitas Layanan } \\
\text { - Sarana } \\
\text { akomodasi } \\
\text { - Restoran } \\
\text { - Toko } \\
\text { kerajinan } \\
\text { tangan } \\
\text { - Toko souvenir } \\
\text { - Fasilitas } \\
\text { keuangan }\end{array}$} \\
\hline & & & $\begin{array}{l}\text { Fasilitas Layanan } \\
\text { - Restoran } \\
\text { - Toko } \\
\text { kerajinan } \\
\text { tangan } \\
\text { - Toko souvenir } \\
\text { - Fasilitas } \\
\text { keuangan }\end{array}$ & \\
\hline \multirow{2}{*}{$\begin{array}{l}\text { Traveller- } \\
\text { generating } \\
\text { region } \\
\text { - Agen } \\
\text { perjalanan } \\
\text { - Operator } \\
\text { perjalanan }\end{array}$} & Promosi & & \multirow{3}{*}{ Kelembagaan } & \multirow{3}{*}{ Kelembagaan } \\
\hline & Informasi & & & \\
\hline $\begin{array}{l}\text { Industri } \\
\text { Pariwisata }\end{array}$ & & & & \\
\hline \multirow[t]{2}{*}{ Wisatawan } & Wisatawan & & & Wisatawan \\
\hline & & Infrastruktur & $\begin{array}{l}\text { Infastruktur } \\
\text { - Jaringan air } \\
\text { bersih } \\
\text { - Jaringan listrik } \\
\text { - Jaringan } \\
\text { telekomunikasi }\end{array}$ & $\begin{array}{l}\text { Infrastruktur } \\
\text { - Jaringan air } \\
\text { bersih } \\
\text { - Jaringan listrik } \\
\text { - Jaringan } \\
\text { telekomunikasi }\end{array}$ \\
\hline
\end{tabular}

Sumber: Leiper; Pitana, 2009; Gunn, 1994; Mcinosh,

Goeldner dan Ritchie, 2000; Inskeep, 1991; dan Peneliti, 2017

\subsection{Definisi Operasional Variabel}

Variabel yang didapat dari sintesis komponen pariwisata, yaitu transportasi, atraksi, fasilitas layanan, kelembagaan dan wisatawan. Masing-masing variabel terbagi menjadi beberapa sub variabel, kecuali variabel wisatawan. Adapun pembagian variabel dengan sub varibel yang terpilih adalah sebagai berikut: 
Region, Vol. 13, No. 1, Januari 2018: 20-36

Tabel 3. Definisi Operasional Variabel

\begin{tabular}{|c|c|c|}
\hline \multicolumn{2}{|c|}{ Variabel / Sub Variabel } & Definisi Operasional \\
\hline \multirow{2}{*}{ Transportasi } & Moda transportasi & \multirow{2}{*}{$\begin{array}{l}\text { Aksesibilitas multi moda yang } \\
\text { mudah untuk mencapai tempat } \\
\text { tujuan }\end{array}$} \\
\hline & Rute perjalanan & \\
\hline \multirow{3}{*}{ Atraksi } & Jarak atraksi & \multirow{3}{*}{$\begin{array}{l}\text { Faktor yang manrik wisatawan dan } \\
\text { menjadi fungsi utama dalam sistem } \\
\text { pariwisata }\end{array}$} \\
\hline & Festival khusus & \\
\hline & Atraksi sosial & \\
\hline \multirow{3}{*}{ Fasilitas Layanan } & Sarana akomodasi & \multirow{3}{*}{$\begin{array}{l}\text { Memfasilitasi kebutuhan wisatawan } \\
\text { di daerah atraksi }\end{array}$} \\
\hline & Sarana perdaga-ngan & \\
\hline & Sarana perbankan & \\
\hline Wisatawan & - & Pelaku yang melakukan pariwisata \\
\hline \multirow[b]{2}{*}{ Kelembagaan } & $\begin{array}{l}\text { Kerjasama } \\
\text { stakeholder }\end{array}$ & \multirow[b]{2}{*}{$\begin{array}{l}\text { Pengelola sumberdaya atraksi } \\
\text { sehingga berfungsi }\end{array}$} \\
\hline & Unit pemasaran & \\
\hline \multirow{3}{*}{ Infrastruktur } & Jaringan air bersih & \multirow{3}{*}{$\begin{array}{l}\text { Semua konstruksi bangunan } \\
\text { terbangun yang ada di daerah } \\
\text { atraksi, baik dibawah maupun } \\
\text { diatas tanah }\end{array}$} \\
\hline & Jaringan listrik & \\
\hline & $\begin{array}{l}\text { Jaringan } \\
\text { telekomunikasi }\end{array}$ & \\
\hline
\end{tabular}

Sumber: Sintesis Penulis, 2017

Parameter penelitian didapatkan dari persilangan antar variabel. Persilangan ini dilakukan untuk mendapatkan kondisi dimana komponen pariwisata dalam sistem pariwisata saling terkait dan terpadu, seperti yang diilustrasikan oleh Gunn (1994).

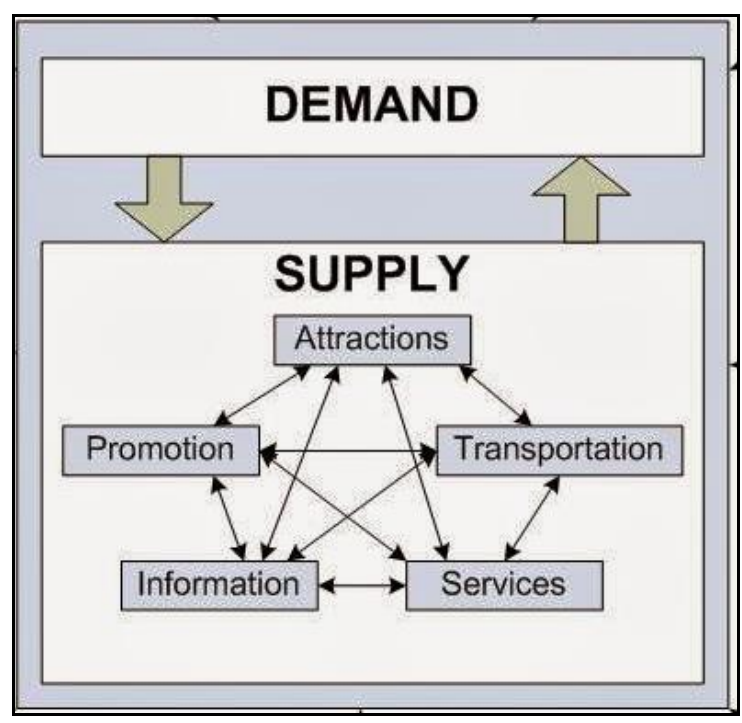

Gambar 3. Sistem Pariwisata Gunn, 1994 (Dimodifikasi dari Gunn, 2017) 
Hafiza Jasmine Azzahra dkk, Komponen Keterpaduan Objek...

Parameter yang telah didapat dari hasil persilangan tersebut kemudian disesuaikan dengan teori keterpaduan yang telah disintesa, apakah parameter termasuk kedalam kategori terpadu spasial, kelembagaan, komunitas atau infrastruktur.

\subsubsection{Keterpaduan Transportasi}

Transportasi berkaitan dengan kemudahan kawasan diakses oleh transportasi umum. Berdasarkan persilangan variabel, keterpaduan transportasi memiliki parameter moda transportasi yang terintegrasi dan keterpaduan rute perjalanan yang ada di sekitar kawasan city walk Slamet Riyadi.

a. Moda Transportasi

Moda transportasi yang dapat mengakses Kota Surakarta adalah Batik Solo Trans (BST) atau bus kota dan angkutan umum, kereta api, dan pesawat yang kemudian disambung dengan moda angkutan yang lainnya. Kota Surakarta sendiri saat ini memiliki 12 rute trayek yang beroperasi di dalam kota. Dari 12 rute trayek tersebut, tiga diantaranya merupakan rute trayek BST atau Batik Solo Trans, dan sembilan trayek sisanya merupakan trayek angkutan umum perkotaan. (Gambar 4).

b. Rute Perjalanan

Keterpaduan rute perjalanan merupakan pengukuran kemudahan aksesibilitas kawasan dilihat dari jaringan rute transportasi umum yang melewati kawasan penelitian. Dari 12 rute trayek yang melintas di Kota Surakarta, kemudian diidentifikasi trayek saja yang melintasi kawasan penelitian. Kemudian dari trayek yang melintas di kawasan city walk Slamet Riyadi, diidentifikasi darimana asal dan tujuan rute trayek tersebut. Pengidentifikasian asal dan tujuan trayek guna melihat titik-titik nodal untuk dihitung selanjutnya. 


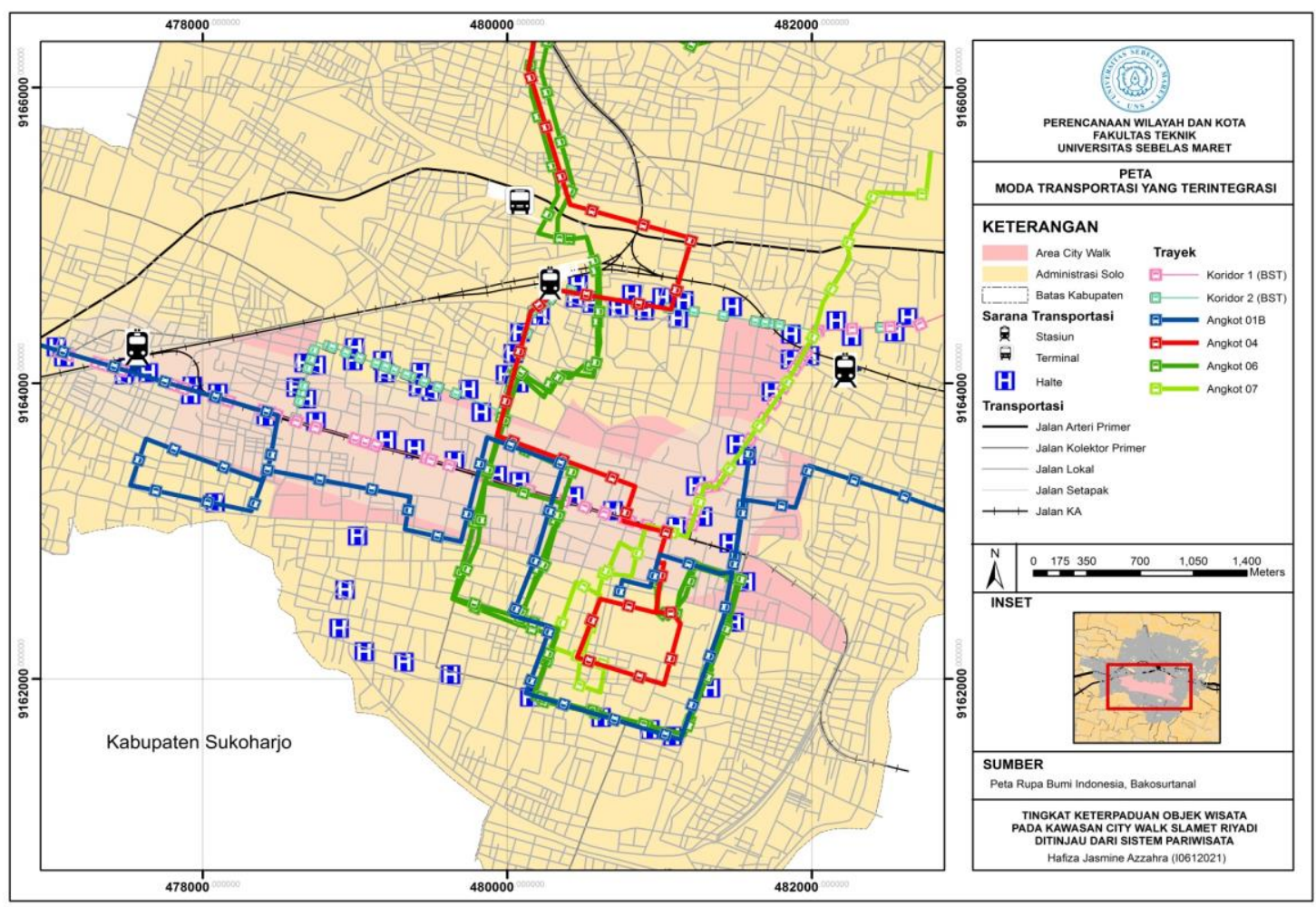

Gambar 4. Peta Moda Transportasi yang Terintegrasi (Bakosurtanal; Peneliti, 2017)

\subsubsection{Keterpaduan Atraksi}

Atraksi yang akan dibahas di kawasan city walk Slamet Riyadi adalah atraksi yang berada dalam radius $\leq 400$ meter (Peraturan Menteri Pakerjaan Umum tahun 2014); akan dianalisis mengenai jarak antar atraksinya; kemudian pengidentifikasian festival khusus, dan identifikasi atraksi sosial.

a. Jarak Atraksi

Titik-titik atraksi yang terdapat sepanjang city walk Slamet Riyadi tersebar pada beberapa segmen. Pada segmen 1 dan segmen 2 tidak terdapat atraksi. Kemudian atraksi baru terdapat pada segmen 3, 4, 5,6 dan 7 (Gambar 5). Dari atraksi-atraksi tersebut, kemudian untuk melihat keterpaduan jarak antar atraksinya, dilakukan analisis jarak atraksi dengan buffering sejauh 400 meter (Peraturan Menteri Pekerjaan Umum tahun 2014). Buffer ini dilakukan dari jalan di depan 
Hafiza Jasmine Azzahra dkk, Komponen Keterpaduan Objek...

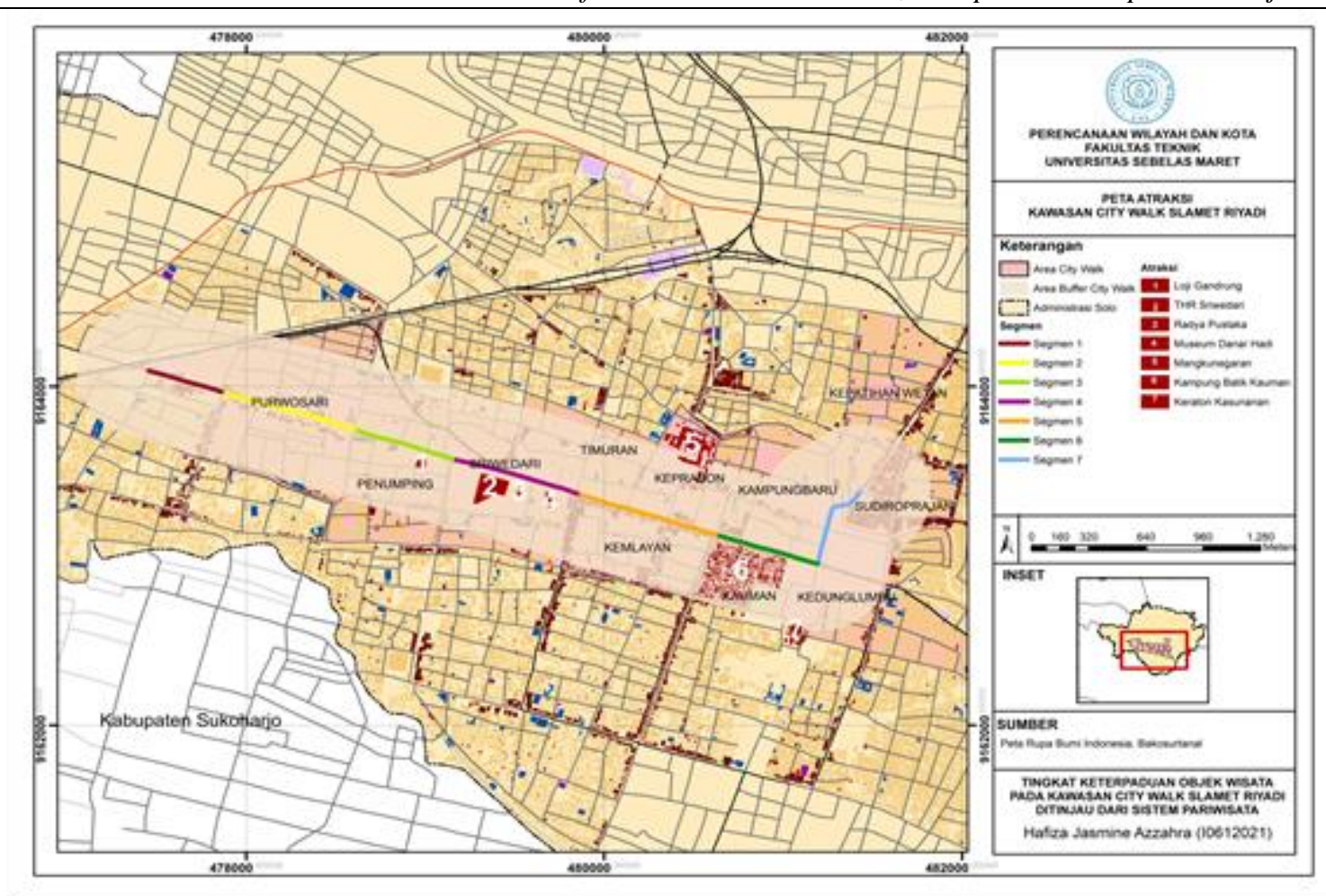

Gambar 5. Peta Atraksi di Kawasan City Walk Slamet Riyadi (Bakosurtanal; Peneliti, 2017)

\section{b. Festival Khusus}

Festival merupakan salah satu atraksi yang dapat menarik wisatawan agar berkunjung pada waktu tertentu. Festival khusus juga memiliki nilai keterpaduan sebagai atraksi yang dapat mempromosikan keunikan daerah pariwisata, dalam hal ini adalah kawasan city walk Slamet Riyadi. Dari festivalfestival yang ada di kawasan city walk Slamet Riyadi Kota Surakarta, kemudian diidentifikasi sesuai dengan nilai indikator penelitian.

\section{c. Atraksi Sosial}

Keterpaduan atraksi juga dapat dilihat dengan adanya atraksi sosial. Atraksi sosial sendiri merupakan atraksi yang memungkinkan wisatawan memiliki kesempatan menjadi bagian dari masyarakat. Menjadi bagian masyarakat disini maksudnya mempelajari kebudayaan masyarakat sekitar dan beberapa bahkan tinggal selama beberapa saat di daerah atraksi tersebut. Di Kota Surakarta, khususnya di kawasan city walk Slamet Riyadi berada di Kampung Batik Kauman.

\subsection{Keterpaduan Fasilitas Layanan}

Fasilitas layanan mendukung pariwisata dalam melengkapi kebutuhan nonatraksi wisatawan. Fasilitas layanan yang ada di sekitar kawasan city walk Slamet 
Region, Vol. 13, No. 1, Januari 2018: 20-36

Riyadi akan dilihat keterpaduannya dalam mendukung atraksi dalam jarak dan waktu tempuh yang proporsional dan fasilitas yang sama jenisnya lebih baik berdekatan. Adapun fasilitas layanan yang akan dibahas adalah sarana akomodasi, sarana perdagangan (rumah makan dan tempat perbelanjaan), dan sarana perbankan.

\section{a. Sarana Akomodasi}

Sarana akomodasi merupakan sarana bagi wisatawan untuk menginap. Termasuk sarana akomodasi adalah hotel, motel, inn, dan tempat menginap lainnya.

Tabel 4. Fasilitas Akomodasi di Kawasan City Walk Slamet Riyadi

\begin{tabular}{|c|l|l|c|}
\hline No & \multicolumn{1}{|c|}{ Segmen } & \multicolumn{1}{|c|}{ Atraksi } & $\begin{array}{c}\text { Jumlah } \\
\text { Alkomdasi }\end{array}$ \\
\hline 1 & Segmen 1 & - & 7 \\
\hline 2 & Segmen 2 & - & 13 \\
\hline 3 & Segmen 3 & Loji Gandrung & 5 \\
\hline \multirow{2}{*}{4} & \multirow{2}{*}{ Segmen 4 } & THR Sriwedari & 10 \\
\cline { 3 - 4 } & & Museum Radya Pustaka & 6 \\
\cline { 3 - 4 } & & Museum Batik Kuno Danar Hadi & 6 \\
\hline 5 & Segmen 5 & Pura Mangkunegaran & 5 \\
\hline 6 & Segmen 6 & Kampung Batik Kauman & 6 \\
\hline 7 & Segmen 7 & Keraton Kasunanan Hadiningrat & 1 \\
\hline
\end{tabular}

Sarana akomodasi di Kota Surakarta secara jumlah sudah cukup memadai dengan berbagai jenis hotel dari hotel berbintang hingga hotel nonberbintang seperti homestay. Dari indikator yang telah ditentukan sebelumnya, sarana akomodasi yang ada di sekitar kawasan city walk Slamet Riyadi mendukung atraksi dalam jarak tempuh yang proporsional terpadu. Sedangkan parameter penelitian fasilitas layanan yang kedua, dilihat dari fasilitas yang sama jeisnya berdekatan. Zonasi dan kemungkinan pilihan untuk fasilitas layanan sejenis minimalnya adalah 2 , agar wisatawan mempunyai referensi dan pilihan untuk memilih. Penyebaran sarana akomdasi yang ada di kawasan city walk Slamet Riyadi kurang merata, sehingga kurang adanya zonasi, kurang mendukung atraksi untuk berkembang.

\section{b. Sarana Perdagangan}

Sarana perdagangan dibedakan menjadi dua, yaitu rumah makan dan tempat perbelanjaan. Rumah makan merupakan fasilitas untuk wisatawan yang ingin mencari makan, termasuk restoran dan café, sedangkan tempat perbelanjaan 
Hafiza Jasmine Azzahra dkk, Komponen Keterpaduan Objek... adalah tempat di mana wisatawan dapat berbelanja oleh-oleh dan kebutuhan pribadi sehari-sehari.

Tabel 5. Fasilitas Perdagangan di Kawasan City Walk Slamet Riyadi

\begin{tabular}{|c|c|c|c|c|}
\hline \multirow[b]{2}{*}{ No } & \multirow[b]{2}{*}{ Segmen } & \multirow[b]{2}{*}{ Atraksi } & \multicolumn{2}{|c|}{ Sarana Perdagangan } \\
\hline & & & $\begin{array}{l}\text { Tempat } \\
\text { Belanja }\end{array}$ & $\begin{array}{l}\text { Rumah } \\
\text { Makan }\end{array}$ \\
\hline 1 & Segmen 3 & Loji Gandrung & 2 & 10 \\
\hline \multirow{3}{*}{2} & \multirow{3}{*}{ Segmen 4} & THR Sriwedari & 2 & 15 \\
\hline & & Museum Radya Pustaka & 2 & 9 \\
\hline & & Museum Batik Kuno Danar Hadi & 2 & 10 \\
\hline 3 & Segmen 5 & Pura Mangkunegaran & 3 & 13 \\
\hline 4 & Segmen 6 & Kampung Batik Kauman & 3 & 15 \\
\hline 5 & Segmen 7 & Keraton Kasunanan Hadiningrat & 2 & 2 \\
\hline
\end{tabular}

Sarana perdagangan di Kota Surakarta, terutama rumah makan sangat memadai. Di sepanjang jalan city walk Slamet Riyadi, banyak baik rumah makan, restoran atau warung lesehan yang dapat dinikmati oleh wisatawan. Dari indikator yang telah ditentukan sebelumnya, maka sarana perdagangan dalam mendukung atraksi dalam jarak tempuh yang proporsional terpadu.

\section{c. Sarana Perbankan}

Sarana perbankan merupakan sarana keuangan. Termasuk diantaranya adalah kantor bank dan ATM.

Tabel 6. Fasilitas Perbankan di Kawasan City Walk Slamet Riyadi

\begin{tabular}{|c|l|l|c|}
\hline No & Segmen & Atraksi & $\begin{array}{c}\text { Jumlah } \\
\text { Sarana } \\
\text { Perbankan }\end{array}$ \\
\hline 1 & Segmen 1 & - & 11 \\
\hline 2 & Segmen 2 & - & 21 \\
\hline 3 & Segmen 3 & Loji Gandrung & 15 \\
\hline \multirow{2}{*}{4} & \multirow{2}{*}{ Segmen 4 } & THR Sriwedari & 14 \\
\cline { 3 - 4 } & & Museum Radya Pustaka & 7 \\
\cline { 3 - 4 } & & Museum Batik Kuno Danar Hadi & 6 \\
\hline 5 & Segmen 5 & Pura Mangkunegaran & 8 \\
\hline 6 & Segmen 6 & Kampung Batik Kauman & 9 \\
\hline 7 & Segmen 7 & Keraton Kasunanan Hadiningrat & - \\
\hline
\end{tabular}


Region, Vol. 13, No. 1, Januari 2018: 20-36

Sedangkan parameter penelitian fasilitas layanan yang kedua, dilihat dari fasilitas yang sama jenisnya berdekatan. Zonasi dan kemungkinan pilihan untuk fasilitas layanan sejenis minimalnya adalah 2 , agar wisatawan mempunyai referensi dan pilihan untuk memilih. Penyebaran sarana perdagangan yang ada di kawasan city walk Slamet Riyadi kurang merata, sehingga kurang adanya zonasi, kurang mendukung atraksi untuk berkembang.

\subsection{Keterpaduan Wisatawan}

Wisatawan sebagai komponen yang melakukan pariwisata memiliki banyak waktu. Sehingga dalam mengukur keterpaduan wisatawan adalah bagaimana mengusahakan wisatawan dapat menikmati obyek sebanyak-banyaknya dalam waktu luangnya tersebut dan dengan kualitas yang optimal.

Konsep jalur wisata merupakan kegiatan menikmati berbagai macam objek wisata, didukung dengan fasilitas layanan, berpindah dari satu objek wisata ke objek wisata selanjutnya dan masih keterkaitan dengan sirkuit atau jalan.

Mengunjungi lebih dari satu atraksi maksudnya adalah setelah wisatawan mengunjungi sebuah titik atraksi, misalnya Pura Mangkunegara, apakah setelah itu wisatawan mengunjungi atraksi yang lain, misalnya Batik Kauman.

\subsection{Keterpaduan Kelembagaan}

Kelembagaan merupakan komponen yang mengelola atraksi agar dapat berfungsi optimal dan menarik wisatawan. Pada sub bab ini akan mengidentifikasi kerjasama manajemen pariwisata dalam mengelola kawasan wisata di kawasan city walk Slamet Riyadi dan mengidentifikasi unit pemasaran / visitor center yang ada di Kota Surakarta dalam mendukung pariwisata di kawasan city walk Slamet Riyadi.

\section{a. Kerjasama Stakeholder}

Kerjasama manajemen pariwisata berkaitan dengan instansi pemerintah dan masyarakat. Kerjasama ini untuk melihat peran dari masing-masing lembaga dalam mengelola atau mengoptimalkan daya tarik kawasan city walk Slamet Riyadi Surakarta. Dalam mengidentifikasi kerjasama instansi pemerintah yang mengelola pariwisata di kawasan city walk Slamet Riyadi Surakarta, dinas yang terkait adalah Dinas Pariwisata, Dinas Kebudayaan dan Dinas Komunikasi dan Infromasi.

Peran Dinas Pariwisata adalah sebagai pihak yang mendukung terjadinya atraksi-atraksi pariwisata terutama atraksi yang berbentuk event atau festival, umumnya berupa dukungan dana, meskipun tidak mendukung seluruh 
Hafiza Jasmine Azzahra dkk, Komponen Keterpaduan Objek... operasional acara. Penyelenggara event atau festival itu sendiri merupakan pihak ketiga, yaitu masyarakat (sanggar, komunitas, paguyuban, pokdarwis) atau pihak swasta.

Untuk peran Dinas Kebudayaan merupakan pihak yang mendata sanggarsanggar seni dan memberikan wadah untuk kegiatan mereka. Sedangkan untuk Dinas Informasi dan Komunikasi, apabila Dinas Pariwisata dan Dinas Kebudayaan ingin mengadakan kegiatan dan butuh untuk dinformasikan ke pihak luas, maka dinas tersebut tinggal menghubungi Dinas Komunikasi dan Informasi untuk dipromosikan di baliho yang ada di Kota Surakarta.

Sedangkan kerjasama antar lembaga, terjadi secara formal yaitu dengan penandatanganan surat kerjasama atau MoU. Perjanjian ini terjadi antara Dinas Pariwisata dengan dinas lainnya di luar Kota Surakarta. Sedangkan dalam Kota Surakarta sendiri, Dinas Pariwisata bekerjasama dengan Dinas Komunikasi dan Informasi untuk mempromosikan event-event yang akan diselenggarakan.

\section{b. Unit Pemasaran}

Unit pemasaran merupakan unit yang bertujuan untuk memasarkan dan mempromosikan atraksi yang ada di Kota Surakarta. Di Kota Surakarta terdapat dua unit pemasaran yang dikelola pemerintah. sedangkan agen perjalanan merupakan lembaga bisnis dengan tujuan mencari keuntungan dan secara tidak langsung ikut memasarkan atraksi yang ada di Kota Surakarta, dalam hal ini khusunya atraksi yang ada di kawasan city walk Slamet Riyadi Surakarta.

Dinas Pariwisata dalam memberikan informasi atraksi kepada wisatawan juga telah menyediakan deskripsi atraksi dalam guidebook mengenai atraksi yang ada di Kota Surakarta. Selain itu, pemsaran atraksi juga sudah merambah ke dunia digital, yaitu melauli website dan aplikasi Solo Destination yang dapat diakses oleh semua pengunjung untuk memudahkan wisatawan dalam memenuhi kebutuhannya berwisata. Sedangkan bagi wisatawan yang menginginkan tur wisata tertentu dapat dipenuhi dengan pemesanan paketpaket tur yang dapat disesuaikan dengan agen perjlanan yang ada. Untuk agen perjalanan sendiri, di Kota Surakarta tercatat kurang lebih sebanyak 39 agen perjalanan. 


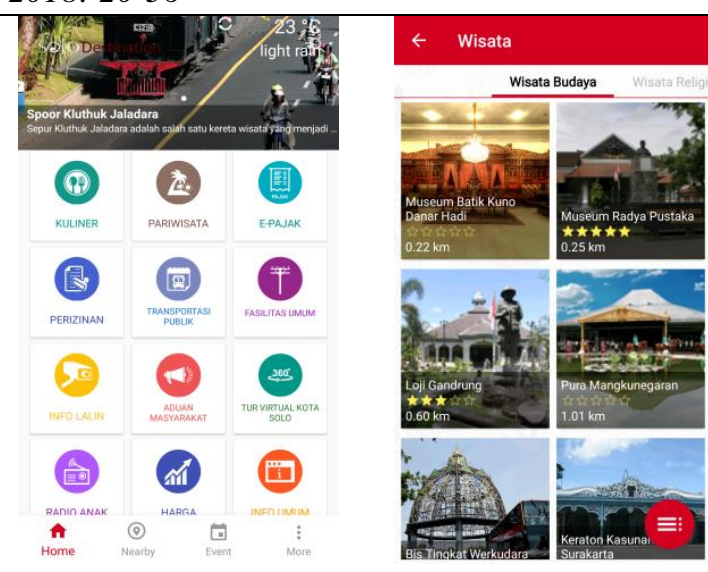

Gambar 6. Aplikasi Solo Destination (Kompilasi Penulis, 2017)

\subsection{Keterpaduan Infrastruktur}

Infrastruktur merupakan prasarana yang mendukung keberlangsungan atraksi dan fasilitas layanan. Infrastruktur disini adalah jaringan air bersih, jaringan listrik dan jaringan telekomunikasi. Karena ketiga jaringan tersebut penting dalam mendukung kerberlagsungan atraksi dan fasilitas layanan, maka jaringan infrastruktur dikatakan siap apabila ketiga jaringan tersebut telah melayani seluruh atraksi dan fasilitas layanan yang ada di kawasan city walk Slamet Riyadi Surakarta. Berikut penjelasannya.

\section{a. Jaringan Air Bersih}

Atraksi dikatakan siap apabila telah dilengkapi oleh jaringan infrastruktur air bersih, listrik, dan telekomunikasi. Dari pengamatan dan pengambilan data, diketahui bahwa seluruh atraksi di kawasan city walk Slamet Riyadi sudah terpenuhi jaringan air bersih.

\section{b. Jaringan Listrik}

Dari pengamatan dan pengambilan data, diketahui bahwa seluruh atraksi di kawasan city walk Slamet Riyadi sudah terpenuhi jaringan listrik untuk penerangan akan tetapi mungkin masih perlu ditingkatkan untuk titik-titik atraksi karena listrik yang ada mengakomodir untuk tingkat kota.

\section{c. Jaringan Telekomunikasi}

Keberadaan infrastruktur dibutuhkan untuk melengkapi kebutuhan wisatawan. Infrastruktur jaringan telekomunikasi dibutuhkan untuk memudahkan wisatawan untuk berkomunikasi. Kota Solo mempunyai institusi atau lembaga, baik dari sektor pemerintah maupun swasta, untuk mengakomodir kebutuhan tersebut. 


\section{KESIMPULAN}

Hafiza Jasmine Azzahra dkk, Komponen Keterpaduan Objek...

Beberapa kesimpulan yang dapat ditarik adalah, pertama, dari keterpaduan transportasi didapatkan bahwa Kota Solo telah memiliki cukup fasilitas pergantian moda transportasi untuk diakses, sedangkan dari rute perjalanan, Kota Solo dilewati langsung oleh beberapa rute trayek yang dapat berhenti di kawasan city walk Slamet Riyadi. Keterpaduan atraksi didapatkan parameter untuk jarak atraksi, yang perlu dilihat jarak kedekatannya, terutama dalam radius pejalan kaki. Festival khusus, Kota Solo sebagai kota event memiliki banyak festival khusus yang diadakan di tempat dan waktu tertentu yang dapat mempromosikan kawasan city walk Slamet Riyadi, namum perlu diidentifikasi dahulu dengan nilai indikator penelitian. Untuk atraksi sosial, di kawasan city walk Slamet Riyadi terdapat atraksi sosial di Kampung Batik Kauman.

Berikutnya, keterpaduan fasilitas layanan membahas sarana akomodasi, sarana perdagangan (rumah makan dan tempat perbelanjaan), dan sarana perbankan dalam mendukung atraksi dalam jarak dan waktu tempuh yang proporsional dan memiliki zonasi fasilitas. Keterpaduan wisatawan dilihat dari banyaknya objek wisata yang dikunjungi wisatawan di sepanjang city walk Slamet Riyadi. Keterpaduan kelembagaan dilihat dari kerjasama manajemen pariwisata dalam mengelola kawasan wisata di kawasan city walk Slamet Riyadi serta mengidentifikasi unit pemasaran / visitor center yang ada di Kota Surakarta apakah sudah mendukung pariwisata di kawasan city walk Slamet Riyadi. Keterpaduan infrastruktur merupakan yang dinilai adalah jaringan air bersih, jaringan listrik dan jaringan telekomunikasi, apakah jaringan-jaringan tersebut sudah mendukung atraksi dan fasilitas layanan yang ada di kawasan city walk Slamet Riyadi Surakarta.

Saran yang dapat peneliti sampaikan adalah perlu penilaian lebih lanjut untuk tingkat keterpaduan setiap variabel dan juga penilaian tingkat keterpaduan objek wisata di kawasan city walk Slamet Riyadi Surakarta.

\section{REFERENCES}

Andersson, T. Serger, S.S, Sorvik J, \& Hansson, E.W. (2004). The Cluster Policies Whitebook. Sweden: IKED (2004),

Bianchi, P., Miller, L.M., \& Bertini, S. (1997). The Italian SME Experience and Possible Lessons for Emerging Countries. Bologna: Nomisma.

Belussi. Fiorenza. 2006. In search of a Useful Theory of Spatial Clustering. dalam Asheim, dkk. Cluster and Regional Development: Critical Reflection and Exploration. New York: Taylor and Francis e-Library

Departemen Perindustrian. 2009. Peta Panduan (Road Map) Pengembangan Klaster Industri Prioritas Industri Berbasis Agro Tahun 2010-2014. Lampiran Peraturan Menteri Perindustrian Republik Indonesia 
Region, Vol. 13, No. 1, Januari 2018: 20-36

Goeldner, Charles, J.R. Brent Ritchie, and Robert W. McIntosh. 2000. Tourism: Principles, Practices, Philosophies. 8th ed. New York: John Wiley \& Sons, Inc.

Gunn, Clare A. 1994. Tourism Planning: Basics, Concepts, Cases. 3rd ed. Washington, DC: Taylor \& Francis.

Hayllar, Bruce, Tony Griffin, and Deborah Edwards. 2010. City Spaces - Tourist Places. City Spaces - Tourist Places. doi:10.4324/9780080878270.

Inskeep, Edward. 1991. Tourism Planning. New York: Van Nostrand Reinhold.

Leiper, Neil. 1979. "The Framework of Tourism: Towards A Definition of Tourism, Tourist, and The Tourist Industry." Annals of Tourism Research 6 (4): 390-407.

1990. Tourism System: An Interdisciplinary Perspective. Palmerston Nrt, N.Z.: Dept. of Management System, Business Studies Faculty, Massey University.

Pitana, I Gde, and I Ketut Surya Diarta. 2009. Pengantar Ilmu Pariwisata. Yogyakarta: CV. Andi Offset.

SNI 03-1733-2004 tentang tata cara perencanaan lingkungan perumahan di perkotaan Undang-Undang No. 10 Tahun 2009 tentang Kepariwisataan 